\title{
Prosa de ficção cabo-verdiana e caminhos identitários: imprevisíveis e intermináveis
}

\author{
Maria Aparecida Santilli \\ Universidade de São Paulo
}

\begin{abstract}
RESUMO: A PARTIR DE UMA REFLEXÃO DE CONSTANTES QUE PERCORREM O SISTEMA LITERÁRIO CABOVERDIANO, ELABORA-SE UMA LEITURA COMPARATIVA ENTRE OS ROMANCES O TESTAMENTO DO SR. NAPUMOCENO DA SILVA ARAÚJO, DE GERMANO ALMEIDA, E VOZ DE PRISÃO, DE MANUEL FERREIRA.
\end{abstract}

ABSTRACT: BASED ON A REFLECTION OF CONSTANTS WHICH COVER THE CAPE VERDIAN LITERARY SYSTEM, A COMPARATIVE READING BETWEEN THE NOVELS O TESTAMENTO DO SR. NAPUMOCENO DA SILVA ARAÚJO, BY GERMANO ALMEIDA, AND VOZ DE PRISÃO, BY MANUEL FERREIRA IS ELABORATED.

PALAVRAS-CHAVE: LITERATURA CABOVERDIANA, GERMANO ALMEIDA, MANUEL FERREIRA. KEY-WORDS: CAPE VERDIAN LITERATURE, GERMANO ALMEIDA, MANUEL FERREIRA. 
er e reler livros que sempre vêm à baila no espaço de trabalho, de (in)formação, de reflexão e de produção em que resulta a convivência com a Literatura, incentiva a descartar certas utopias. Uma delas seria, talvez, a de imaginar fins e veredas de percurso à frente, ou, mais pontualmente, de levantar hipóteses futurológicas sobre vitalidade e vetores de determinadas linhas temáticas e de procedimentos literários, sobretudo quando, nos estreitos limites de breve incursão a ficcionistas cabo-verdianos como é esta, o objetivo consiste em apenas apontar uma linha relevante e reconhecida, na série literária a que pertencem.

Esta idéia ocorre ao rememorar agora o trajeto da prosa de ficção identitária em Cabo Verde e pensar nas distâncias e veredas que esse viés literário percorreu entre aproximadamente os anos trinta do século XX e a atualidade.

Que leitor da Literatura Cabo-Verdiana não se lembra, por exemplo, desde prosadores marcantes do movimento da Claridade, como Baltasar Lopes e Manuel Lopes, passando por tantos outros que se seguiram, até os de memória mais recente, ou agora atuantes como Germano Almeida que pode remeter saudosamente a outro ficcionista de um passado menos distante, Manuel Ferreira, e, por razões que serão mais adiante expostas, estimular a uma aproximação de dois notáveis personagens, o Senhor Napumoceno Silva Araújo, do conhecido Testamento, e Nhá Joja, de Voz de Prisão?

Quando se trata de obras como Chiquinho e Os flagelados do vento leste, recordase como os escritores da Claridade empenharam-se em retomar motivos muito próprios da vivência cabo-verdiana, então não tomados sob uma perspectiva ufanista ou narcísica, nem muito menos segundo uma ótica evasionista ou alienante. "Caboverdeamadamente" implicava, então, em problematizar dados e fatos que se marcavam pela força conflitiva e por decorrências de maquinação do poder com as quais o cabo-verdiano estava cotidianamente a defrontar-se. As inclemências naturais e sociais, os agravantes da repetência de fenômenos cíclicos da natureza e de males endêmicos da sociedade, oponentes ao bem-estar na vida das Ilhas, o limite estreito de alternativas de solução, os indícios das forças e anseios de libertação a fermentar, é que se faziam transparentes, sem ocultar, por outro lado, a "morabeza" cabo-verdiana, a solidariedade entre os desprivilegiados sociais e até entre diferentes estratos da sociedade nacional da época. As iniciativas de ficcionar esse quadro como caracterizador de um povo em determinada conjuntura histórica, visto por si próprio em pauta realista, mostram variantes da prosa literária como um conjunto de reiluminações e 
de complementaridades, indicando a fecundidade e multiplicidade de associações da temática identitária. No conjunto das variantes endossa-se o ponto de vista de que identidade é categoria em permanente construção e que, nessa específica instância - dos anos 30 para a atualidade -, múltiplos olhares de e para Cabo Verde a conceberam numa linha análoga de convicções que então pontualmente a sedimentavam. Chiquinho, como José da Cruz, mesmo com a destinação oposta que na história de vida de cada um se construiu, acabaram por simbolizar a capacidade de resistência cabo-verdiana, o apego telúrico, a fidelidade cabo-verdiana ao chão de nascença como referência inarredável, ainda que reiteradamente, como se releva em Chiquinho, exposta aos apelos contrários de ir/ficar, ao dilema de amar/deixar a terra de origem. Nos dois casos, se mostra a evolução de uma consciência nacional dos protagonistas, embora Chiquinho ainda se defina por não poder sobreviver ao imperativo pessoal ou social de emigrar, atando as pontas de sua experiência a uma tradição que, com ele, preservou-se na manutenção do "status" de uma família-símbolo no estrato social que ele representou.

O incentivo para aproximar Nhá Joja, de Napumoceno Silva Araújo, talvez derive, em última instância, das sugestões de Northrop Frye, acerca da "analogia da experiência", em contraposição à "analogia da experiência”. Esboça-se em Manuel Ferreira e aprofunda-se em Germano Almeida uma perspectiva calcada na ironia com que se percebem e retratam personagens em situações.

Manuel Ferreira, luso-caboverdiano como é sabido, vem de uma experiência literária ligada à dos neo-realistas portugueses. Com Grei e A Casa dos Motas, tão casado estava às referências efetivas de seu país quanto a vanguarda neorealista: Alves Redol, Manuel da Fonseca, Carlos de Oliveira, Fernando Namora ou Cardoso Pires. É um veio lusitano da ficção de Manuel Ferreira que não se pode esquecer, até para confrontar com seu posterior engajamento com a causa cabo-verdiana. Será bem lembrado pensar em Morna (1948) e Morabeza (1958), obras com as quais ele emigra, implanta-se no contexto cabo-verdiano, um caminho sem volta, como também ao longo do tempo se revelou.

Como foi próprio de Baltasar Lopes e Manuel Lopes, Manuel Ferreira adotou causas/ temáticas típicas cabo-verdianas, como o sentimento de insularidade e o conseqüente desejo de evasão, a seca,a fome, a decadência do Porto de São Vicente, a família cabo-verdiana sob o risco permanente da dispersão, a miséria como agente de desagregação social. Passam pelas páginas de Manuel 
Ferreira, maturando em Hora di Bai (1962), quando se arrisca, portanto, na aventura de escrita mais temível, de operação mais extensa e multifacetada de imaginação e de retórica. Como comporta também lembrar, é um romance escrito sob a motivação explícita de textos cabo-verdianos e traz, como portal, uma dedicatória à ficcionista Orlanda Amarílis que sela a sedutora escalada para a cabo-verdianidade:

A minha mulher: a quem, ao longo destes anos, fui surrupiando, às vezes traiçoeiramente, muita da matéria desta narrativa, quem sabe se impossibilitando-a de um dia torná-la sua...

Pode-se verificar como Hora di Bai inspira-se em textos cabo-verdianos dos mais decantados e, manifestamente prezados, portanto, por Manuel Ferreira, como as letras de mornas de autoria de Dante Mariano, o poema do livro $\mathrm{Ca}$ minhada, de Ovídio Martins, a finançon, batuque da terra, da revista Claridade, que não se desfizeram no novo texto. Resguardaram-se, apropriados com o lastro de sentidos da origem, para valerem como um substrato etnológico e etimológico, como raízes de motivação cabo-verdiana que movimentam, enquanto núcleos temáticos que passam a ser, o romance que gira em torno do eixo querer ficar/ter que-partir. Por um lado, apreendido pelo foco lírico das mornas por onde vaza a amorabilidade do Ilhéu, mas, por outro lado, temperando-se com a sabedoria e senso-de-humor do povo, para dar volta às questões locais colocadas: "O macaco mora na rocha / O negro no funco / O mulato na loja / O branco no sobrado / Um dia virá que o macaco corre com o negro do funco / O negro corre com o mulato da loja / O mulato corre com o branco do sobrado / O branco foge para a rocha e cai no mar. (1972, p. 233).

Não se tratará, aqui, de analisar Hora di Bai e sim de encaminhar à aproximação de duas obras com traço comum já referido, Voz de Prisão (1971) e O Testamento do Sr. Napumoceno da Silva Araíjo (1989), de que se cuidará mais adiante.

Mas, desses poucos dados preliminares sobre a obra de Manuel Ferreira, é, por fim, importante evocar o fato de que, ao reunir os contos de Morna e Morabeza para uma edição conjunta, o fez com o título de Terra trazida (1972), batismo que talvez possa dar mais clareza e ênfase à sua reiterativa adoção.

Quanto a Manuel Ferreira, há, assim, de partida, um dado extra-literário de particular interesse pelas razões de sua projeção na visão que se imprime 
aos fatos narrados. Seria presumível que o foco narrativo derivasse de uma ótica portuguesa; no entanto, mais se apresenta como um olhar de desvio em relação a tal ponto de vista, vincado por uma adesão programática, por uma perspectiva implantada no universo de Cabo Verde, o que distingue essa obra de tantas leituras e interpretações exógenas do universo cabo-verdiano.

No tocante ao romance de Germano Almeida, vale a pena conjeturar sobre a focalização de um legado que não se configura apenas com haveres materiais, mas que incidiria sobre uma herança de ancestralidade cultural de geração ambígua, que ultrapassa a de vivência íntima das Ilhas e deixa em aberto, como se pairasse sobre os fatos e personagens, a pergunta desconfortante sobre o desdobramento de quais fundações éticas se apoiaria o desempenho do protagonista.

A começar por Voz de Prisão, a estória está em correspondência com um ciclo de vida histórico que já não é o dos primórdios da conspiração pela independência. Da consciência social agudizada pelos problemas de carências básicas e discriminações da sociedade de classes, os africanos então transitavam no campo da consciência política, da luta de libertação que atingia a extensividade e intensividade em manifestações também ostensivas e, desde os anos 60, de luta armada pela descolonização.

Este romance, assim como $O$ Testamento, constrói-se a partir de uma personagem: Nhá Joja, cabo-verdiana sexagenária integrada na Metrópole. De exuberante vitalidade, entretanto, melhor se configura pelos estados de euforia de mulher afinal bem-sucedida na ascensão de patamares sociais, estado que the empana a visibilidade para novos valores aos quais se abre Vítor, que ela tem como filho e cujo desempenho, de início vacilante,acabará pó constituir-se antimodelo das convenções que ela própria assimilou, acabando por alinhar-se na luta de resistência que uma voz profética antecipa acabar em "voz de prisão".

O que faz Nhá Joja crescer, arredondar-se como personagem, é o amplo lastro de suas vivências que resulta em oferecer, do cabedal da memória, um fluxo vigoroso de lembranças de contatos humanos, de conhecimento de casos, um rico arquivo de pessoas/situações de que se tece o cotidiano de Cabo Verde. Amante da vida, extrovertida, Nhá Joja é o tipo adequado a ser campo magnético da "confraria"cabo-verdiana em terra estrangeira, sempre na iminência de diásporas que a ameaçam. Bem-falante, de tudo contar "com lábia"como reza a estória, alimenta cerrado diálogo à sua volta, onde vêm à 
baila presentes e ausentes, num desfile de tipos, ora bem transculturados, como o filho Rolando, ora ainda genuinamente das Ilhas, como Pidrim, e outros, evocados com a graça da oralidade, na frescura das manifestações espontâneas. Esse aproveitamento do "papiar"em cenários domésticos é a via própria de Manuel Ferreira penetrar no que é mais recôndito, de desvelar um leque de intimidades da vida dos cabo- verdianos, de aprofundar-se nos seus modos de ser, de ver o mundo.

A multiplicação e diversificação das reuniões permitem articular, pela palavra dos interlocutores, um rol de práticas cabo-verdianas: do humor das coladeiras, a que nem os velhos resistem, ao grotesco, do enterro de Nhô Lúcio Alfama;do épico das causas africanas, com as lembranças próximas do Capitão Ambrósio a outras mediatas, de Lumumba, Fanon, Senghor e Sartre, ao lírico, como o poema "Sô Santo", de Viriato da Cruz. Incluem-se nesse rol as crenças, as experiências de ordem mística das sessões espíritas, ou das interpretações pela ótica dos "cangados de espírito", como é a da agressão de Pidrim. Também não se deixa de tratar dos conflitos políticos da independência e da questão racial e não faltam alusões a vizinhos culturais, como o Brasil.

O recurso de situar um círculo cabo-verdiano fora dos limites geográficos de CaboVerde parece favorecer a operacionalização desta postura de narrar, na obra de Manuel Ferreira.Viabiliza a convergência de uma seleção de tipos e de feitos mais adequados a comporem-na na plenitude desejada. Consuma-se, afinal, fórmula possível de mimetizar o auto-reconhecimento que se apreende num foco de fulguração onde a atualidade se sustenta.

A leveza ou flexibilidade dessa solução literária é que parece suscitar no leitor a sensação de ter escapado da "fixidez e do fetichismo de identidades no interior da calcificação de culturas coloniais", como viu Homi Bhabha, delineando O Local da cultura (1998, p. 29).

Retomando O Testamento do Sr. Napumoceno da Silva Araújo, é sedutor o desafio de repensar, nas opções por gêneros, em que implicou essa escolha de Germano Almeida.

A primeira pista que ocorre é a da visível atração do Romancista pela estética do riso que tem relevo em outras obras suas e o fato é que se convertem em formas de dar, entre outras oportunidades, a de navegar nas águas do conhecimento praticando o que se diz ser privilégio de espécie, do homem como o animal que ri. 
Vale dizer que é um percurso que requisita afastar detritos de um preconceito que atravessou os séculos, o de entender a arte do riso como arte menor.Prisioneiros desse julgamento e de dogmas que o justificam, certamente inúmeros leitores terão deixado de abrir sua percepção para casos imperdíveis dessa via literária eficaz de olhar o mundo e assim o compreender.

Entre os livros de Germano Almeida, o que pode mais imediatamente levar oleitor brasileiro a estabelecer analogias com um perfil literário já para ele familiar é Dona Pura e os Camaradas de Abril, embora seja, pelo quanto aqui se sabe, dos menos comentados.

Ocorre que esse livro pode desencadear uma relação quase "pavlóvica" entre uma de suas figuras, o primo Natal, e a célebre do passado da Literatura Brasileira, o Leonardo de Memórias de um sargento de milícias. Ou seja, o primo Natal pode enquadrar-se na dialética da malandragem, em que Antônio Cândido situou a personagem de Manuel Antônio de Almeida, cuja obra mencionada Alfredo Bosi, na História concisa da literatura brasileira,inclui entre as que "estão isentas de qualquer traço idealizante" (1980, p. 145-146).

Como se pretende, porém, apontar O Testamento, da memória de leituras vêm à tona testamentos burlescos, como os da Idade Média, ou o testamento cômico, como o do final do Pranto de Maria Parda, de Gil Vicente, o que não implica em excluir o sentido do ato jurídico pelo qual alguém dispõe de seus bens para depois de sua morte, ou faz saber suas últimas vontades. Mas não só. Ouviu-se contar da tradição jurídica romana, das Ordenações do Reino, das variações sucessivas do código civil pelo qual essa questão se rege na vida extra-literária. Enfim, a leitura do livro de Germano Almeida desencadeia a memória de idéias feitas que se acumulam ao longo da práxis, por onde tem passagem quase universal essa prática. Mas o confronto das noções que baseiam essa aprendizagem não são de peculiaridades coincidentes com o que foi imaginado no testamento literário.

O testamento do Sr. Napumoceno parece conceber-se à imagem dos testamentos antigos em que informava sobre a vida familiar e as preferências espirituais do testador, com minuciosa relação e distribuição do legado e até predisposição do ritual fúnebre.

Das "387 laudas à máquina e as restantes manuscritas com caneta de tintapermanente", tem-se notícias esparsas do testamento, organizadas pelo narrador que de tudo dispõe da leitura que uma tarde inteira consumiu e levou o notá- 
rio a 'desabafar' que, de fato, "o falecido, pensando que fazia um testamento, escrevera antes um livro de memórias"(1989, p. 9).

Assim, o narrador se instala soberano na casa da ficção nela faz rir, pelas marcas do protótipo que o "testamento" vai acrescentando com quebras de linearidade da narrativa, por inserções da voz de quem narra e faz contraponto com a voz de sua personagem posta no discurso indireto livre onde se perfaz aquilo que a personagem não diria de si própria.

Correm, assim, em paralelo e como numa forma de acareação, dois juízos avaliatórios: o do testador e o do narrador e outros interlocutores aos quais recorre o narrador.

No espaço estreito destas reflexões, considera-se importante dar vez a formulações do riso, por entender-se essa marca distintiva e de originalidade de Germano Almeida como responsável pela inclusão, em sua série literária, do senso de humor com que se molda o universo cabo-verdiano, mesmo com os riscos de redução que uma opção como essa pudesse causar.

Há, de fato, uma habilidade de fazer, do sério, o jocoso neste livro de Germano Almeida, a começar do velho sério,no cômico de situações de que se imantam os próprios objetos de referência, gerando riso em cadeia, como ocorre no erro de um zero na encomenda dos mil guarda-chuvas para venda em Cabo Verde,pela graça contagiante que transita do comerciante aos dez mil guarda-chuvas recebidos e à surpresa das chuvas na estiagem que leva a esgotar o hilariante estoque pronto a encalhar,passando pelas formulações da carta de protesto ao caixeiro-viajante, em radicais deslocamentos de registro de linguagem: "Pensou exmo. Senhor, cortou, qual exmo. senhor!Ele merece mesmo é meu filho da puta, meu sacana de merda, aldrabão de um raio a enfiar a um pequeno comerciante no início de vida um empate de dez mil guardachuvas que não serão vendidos nem à razão de 5 por ano” (p. 62).

O mesmo pode-se dizer dos "clássicos" que se fazem ridículos na contextualização, como o quadro da Monalisa defronte da mesa de trabalho do velho lascivo e comerciante mesquinho e a marcha fúnebre de Betowen diante da reação da banda para a executar, porque o chefe "vendo o djosa assim renegado e aviltado, murmurou amuado que qualquer dia apareceria um defunto a pedir se calhar Roberto Carlos ou algum reggeae ou qualquer coisa assim” (p. 17).

No próprio resumo de situações se instauram modulações do grotesco, conforme é possível aferir: "Porque quem na verdade alguma vez sonhou que 
Napumoceno da Silva Araújo poderia ser capaz de aproveitar das idas da sua mulher de limpeza ao escritório e entrar de amores com ela pelos cantos da divisão e por cima da secretária, ao ponto de chegar ao preciosismo de lhe fazer um filho, melhor dizendo uma filha, em cima do tampo de vidro!” (p. 12).

Para além de outras virtualidades de um testamento, como sejam as de fonte para o conhecimento do passado, do papel da família e da mulher, das estratégias das famílias na concentração ou na distribuição da riqueza e outras, há neste caso o exercício detetivesco de usá-lo como artifício de descobertas, como são as de uma efetiva identidade que se oculta sob as máscaras sociais, assim como são as de Napumoceno da Silva Aaújo.

Se, por um lado, as verdades se ocultam até o fim de uma história de vida e só emergem na abertura póstuma de um inventário, essas verdades levantamse com a revelação de que numa sociedade de normas sociais flutuantes, onde imperativos morais não se aplicam com equanimidade, o vezo de Napumocenos é amostra também de certo tipo fino de malandragem que os mais privilegiados têm como esconder nas dobras do prestígio que se concede incondicionalmente aos que acumularam fortuna na família sócio-econômica dos aureolados com o self made man.

É interessante constatar que a "moral da história", até por isso mesmo, se projeta no plano universal que a comporta: "E o sr. Armando Lima, com o seu rigor de contabilista aposentado, precisou que a luz" - "sobre a vida e pessoa do ilustre extinto" - "parecia total. E andando ao lado do sr. Fonseca ia filosofando que nenhum homem poderá alguma vez pretender conhecer outro em toda a extensão e profundidade do seu mistério” (p. 12).

Por fim, os dois livros ora considerados levam à memória de outras reflexões que se associam à de sua leitura e a relativizam: de $O$ local da cultura, já referida, no que concerne a questões como essa, da singularidade dos textos que foram aproximados: "O estudo da literatura mundial poderia ser o estudo do modo pelo qual as culturas se reconhecem através de suas projeções de alteridade" (p. 33), que bem se casa com outra, Pela mão de Alice - o social e o político na pós-modernidade, de Boaventura de Sousa Santos, que alerta para a flexibilização conceitual e o bombardeio das significações pelo qual o signo "identidade" passa. E enfatiza o sentido de processo, enquanto "substantivo" na atual concepção de identidade, terminando pela dedução de que identidades “são, pois, identificação em curso” (1995, p. 135). 
Mas as ponderações aqui feitas restringem-se à literatura de um povo africano determinado,que então emerge em outro processo, o de emancipação política e, por decorrência também cultural, num estágio de re-definição onde e quando essas formas de re-conhecimento ganham ampla pertinência e conseqüência.

As obras ora consideradas nem por isso deixam de mostrar alteridades na alteridade, isto é, de dar a conhecer como vivem pessoas e grupos de pessoas, gostos, preferências enfim estilos de vida que se cruzam no plano geral de sua diferenciação conjunta.

Longe de estimularem qualquer exercício analítico anacrônico, favorecem, além de tudo o mais, com o contributo de, em última instância, exercitar também a convivência com as diferenças tão próprias do hibridismo das culturas de lá e de cá. 